\title{
Further Understanding of Urokinase Plasminogen Activator Overexpression in Urothelial Bladder Cancer Progression, Clinical Outcomes and Potential Therapeutic Targets
}

This article was published in the following Dove Press journal: OncoTargets and Therapy

Nico C Grossmann, (ID) ${ }^{1,2}$ Victor M Schuettfort, (ID) ${ }^{1,3}$ Benjamin Pradere, (iD) 1,4 Marco Moschini, (ID ${ }^{5}$ Fahad Quhal, (ID ${ }^{1,6}$ Hadi Mostafaei, (ID) ${ }^{1,7}$ Francesco Soria, (ID) ${ }^{8}$ Satoshi Katayama, (iD) ${ }^{1,9}$ Ekaterina Laukhtina, (iD) ${ }^{1,10}$ Keiichiro Mori, iD I,II Reza Sari Motlagh, (iD) 1,12 Cédric Poyet, (iD) ${ }^{2}$ Mohammad Abufaraj, iD ${ }^{1,13}$ Pierre I Karakiewicz, ${ }^{14}$ Shahrokh F Shariat, (D) ${ }^{1,10,15-19}$ David D'Andrea (iD)

'Department of Urology, Comprehensive Cancer Center, Vienna General Hospital, Medical University of Vienna, Vienna, Austria; ${ }^{2}$ Department of Urology, University Hospital Zurich, Zurich, Switzerland; ${ }^{3}$ Department of Urology, University Medical Center Hamburg-Eppendorf, Hamburg, Germany; ${ }^{4}$ Department of Urology, University Hospital of Tours, Tours, France; ${ }^{5}$ Department of Urology, Luzerner Kantonsspital, Luzern,

Switzerland; ${ }^{6}$ Department of Urology, King Fahad Specialist Hospital, Dammam, Saudi Arabia;

${ }^{7}$ Research Center for Evidence Based Medicine,

Tabriz University of Medical Sciences, Tabriz, Iran;

${ }^{8}$ Department of Urology, Molinette Hospital,

University of Turin, Turin, Italy; 'Department of

Urology, Okayama University Graduate School of

Medicine, Dentistry and Pharmaceutical Sciences,

Okayama, Japan; ${ }^{10}$ Institute for Urology and

Reproductive Health, Sechenov University,

Moscow, Russia; "'Department of Urology, The

Jikei University School of Medicine, Tokyo, Japan;

${ }_{12}^{12}$ Men's Health and Reproductive Health Research

Center, Shahid Beheshti University of Medical

Sciences, Tehran, Iran; ${ }^{13}$ Division of Urology,

Department of Special Surgery, Jordan University

Hospital, The University of Jordan, Amman, Jordan;

${ }^{14}$ Cancer Prognostics and Health Outcomes Unit,

Division of Urology, University of Montreal Health Center, Montreal, Canada; ${ }^{15}$ Department of

Urology, Weill Cornell Medical College, New York, NY, USA; ${ }^{16}$ Department of Urology, University of Texas Southwestern, Dallas, TX, USA

Texas Southwestern, Dallas, TX, USA;
17 Department of Urology, Second Faculty of

Medicine, Charles University, Prague, Czech

Republic; ${ }^{18} \mathrm{Karl}$ Landsteiner Institute of Urology and Andrology, Vienna, Austria; ${ }^{19}$ European Association of Urology Research Foundation, Arnhem, Netherlands

Correspondence: Shahrokh F Shariat Department of Urology, Comprehensive Cancer Center, Vienna General Hospital, Medical University of Vienna, Währinger Gürtel 18-20, Vienna 1090, Austria

Tel +4314040026150

Fax +43I4040023320

Email shahrokh.shariat@meduniwien.ac.at
Purpose: The Plasminogen Activation System (PAS) plays a role in tumor growth, invasion and metastasis and has been associated with oncological outcomes in urinary bladder carcinoma (UBC). The use of the different components of this system as molecular markers could improve our understanding of the heterogeneous behavior of UBC and might enable earlier disease detection, individual risk stratification, more accurate outcome prediction and be a rationale for new targeted therapies.

Methods: A comprehensive literature search including relevant articles up to October 2020 was performed using the MEDLINE/PubMed database.

Results: The components of the PAS axis are involved in tumor progression through their signaling processes during angiogenesis, cell migration, metastasis and adhesion. The body of evidence shows an association of PAS component overexpression with adverse pathological features and clinical outcome in UBC. Overexpressed PAS components correlate with a higher pathological tumor grade and advanced tumor stage. In non-muscle-invasive bladder cancer (NMIBC), the PAS components were associated with disease outcome while in muscle-invasive bladder cancer (MIBC), it was associated with disease outcome and pathological features. Possible therapeutic approaches in the PAS for the treatment of UBC have only been sparsely investigated in in vitro and in vivo studies. Intravesical plasminogen activator inhibitor 1 (PAI-1) instillation in animal models yielded interesting results and warrant further exploration in Phase II studies.

Conclusion: The overexpression of PAS components in UBC tumor tissue is associated with adverse pathological features and worse oncological outcomes. These findings are mainly based on preclinical studies and retrospective series, which requires further prospective studies to translate the PAS into clinically useful biomarkers and therapeutic targets.

Keywords: urothelial cancer, uPA, uPAR, PAI, therapy, review

\section{Introduction}

Urinary bladder carcinoma (UBC) is the fourth most common cancer in men and the sixth most common cause of cancer-related death in Europe. ${ }^{1}$ In general, UBC is an aggressive disease with poor prognosis. About $75 \%$ of patients are diagnosed with an early stage non-muscle-invasive disease (NMIBC, staged Ta, Tis/CIS, T1), which has an up to $78 \%$ risk of recurrence and $45 \%$ risk or of progression to muscle-invasive disease (MIBC, stage T2-T4) within 5 years. ${ }^{2}$ Moreover, about 
$50 \%$ of patients diagnosed with MIBC will die within 5 years despite surgery in curative intent. ${ }^{3-5}$ Risk stratification and patient selection is of paramount importance in order to identify those patients who are more likely to fail therapy and counselling for additional systemic therapies. However, several predictive and prognostic models did not reach a sufficient level of discrimination to allow implementation in clinical practice. ${ }^{3,6-10}$ To improve the accuracy of such a clinical model, several biomarkers have been investigated and implemented in these models. ${ }^{11-14}$ The main objective in biomarker research is to identify a marker which is cheap, fast, accurate and can be used at several stages of the disease in order to aid clinicians in patient counselling regarding individualized treatment strategies. $^{14-18}$ Furthermore, biomarkers could serve potential targets for therapeutic approaches. ${ }^{19}$ In the plethora of biomarkers discovered in UBC, the plasminogen activation system (PAS) has recently emerged as such a candidate biomarker. The PAS consists of urokinase, also known as urokinase-type plasminogen activator (uPA), the uPA receptor ( $\mathrm{UPAR}$ ) and plasminogen activator inhibitors 1 and 2 (PAI-1 and 2). The UPA activates plasminogen to plasmin by binding to its receptor UPAR and degrades the basement membrane and the extracellular matrix through a proteolytic cascade. ${ }^{20}$ These components are involved in tumor growth, invasion and metastasis, through their effect on angiogenesis and cell migration. ${ }^{20}$

The aim of this review is to provide a comprehensive overview of the current literature on PAS as tissue biomarker and its association with UBC outcomes as well as potential treatment strategies.

\section{Materials and Methods}

We performed a comprehensive literature search including relevant articles up to October 2020 using the MEDLINE/ PubMed database. We included original articles only and restricted the search to the English literature. For the identification of appropriate publications with respect to the general knowledge about the PAS as well as its role in UBC, the search terms plasminogen activator system, urokinase-type plasminogen activator system, uPA, uPAR, PAI, urothelial cancer, transitional cell carcinoma, bladder cancer, bladder neoplasms, therapeutical targets, pharmacology, therapy, immunotherapy were used singularly and combined using a Boolean operator. References of the found articles were reviewed to additionally expand search results. The article selection process was performed by two reviewers. Disagreements were resolved by a third reviewer.

\section{Evidence Synthesis}

\section{Preclinical Data}

The PAS plays a role in angiogenesis, cell migration and adhesion in various carcinomas. ${ }^{21-23}$ This is mainly achieved through remodeling of the extracellular matrix, which allows endothelial cells to invade the tumor stroma and tumor cells to metastasize. In vitro studies have shown a higher expression of UPAR in invasive UBC cell lines and a $>60 \%$ $(p<0.005)$ and $>80 \%(p<0.005)$ reduction in cell migration and invasion, respectively, after uPAR gene-silencing. ${ }^{24}$ McGarvey et al examined the PAS components in UBC cell lines and tumor tissue. They found that in UBC cell lines UPA, uPAR and PAI-1 showed a significant higher expression rates in invasive cells $(\mathrm{p}<0.05)$ and a 3 -fold increase of uPA $(\mathrm{p}<0.003)$ as well as a 2.7-fold increased uPAR expression $(\mathrm{p}<0.008)$ in MIBC compared to NMIBC tumor tissue, but not difference in PAI-1 expression. ${ }^{25}$ These findings are in line with those reported by Champelovier et al They found that UPAR overexpression was associated with increased cell motility in cell culture $(p=0.014)$ and with higher tumor stage in tumor tissue analyses $(p=0.02){ }^{26}$ These data suggest that PAS components are involved in carcinogenesis and progression of UBC, and could, therefore, serve as candidate biomarkers. Table 1 summarizes the findings in in vitro studies.

\section{Association of the PAS with Pathologic Features in UBC}

The current literature suggests that tissue overexpression of PAS components correlates with higher pathologic grade and more advanced tumor stage in UBC.

In a retrospective series of 939 patients with $\mathrm{UBC}$, for example, authors investigated the association of angiogenin, MMP-2, p53, RB and PAI-1 expression using immunohistochemistry (IHC). They found a significantly higher rate of high-grade (65\% vs 35\%) and advanced (T3-T4) tumors (78\% vs 23\%) in patients with high PAI1 expression. ${ }^{27}$ Similarly, in an IHC study of 827 patients with NMIBC, Iwata et al found a significant association of uPA (odds ratio (OR) 1.19, $\mathrm{p}=0.005$ ), uPAR (OR 1.22; $\mathrm{p}=0.001)$ and PAI-1 (OR 1.25, p = 0.0003) with tumor grade 3 disease. $^{28}$

Intratumoral heterogeneity is a known feature of UBC. ${ }^{29}$ Therefore, measurements of the PAS on IHC may be affected 
Table I Overview of the Studies Investigating the Plasminogen Activation System (PAS) in vitro

\begin{tabular}{|c|c|c|c|c|c|c|}
\hline \multicolumn{7}{|c|}{ In vitro Studies } \\
\hline Author & Year & Pat. No. & $\begin{array}{l}\text { Study } \\
\text { Design }\end{array}$ & $\begin{array}{l}\text { Marker } \\
\text { Investigated }\end{array}$ & Cell Line/Source & Findings \\
\hline $\begin{array}{l}\text { McGarvey } \\
\text { et } \mathrm{al}^{25}\end{array}$ & 1998 & $\begin{array}{l}6 \text { cell lines, } 29 \\
\text { tissue } \\
\text { specimens }\end{array}$ & retrospective & $\begin{array}{l}\text { uPA, uPAR, } \\
\text { PAI-I }\end{array}$ & $\begin{array}{l}\text { UBC cell lines (RT4, HT- } \\
\text { 5637, HT-I376, TCCsup, } \\
\text { J82, T24), tissue }\end{array}$ & $\begin{array}{l}\text { - uPA, uPAR, PAI-I overexpression in } \\
\text { UBC cell lines is associated with } \\
\text { higher tumor stage }(P<0.05) \\
\text { - uPA overexpression in tissue is asso- } \\
\text { ciated with higher tumor stage } \\
(P<0.003) \\
\text { uPAR overexpression in tissue is } \\
\text { associated with higher tumor stage } \\
(p<0.008)\end{array}$ \\
\hline $\begin{array}{l}\text { Champelovier } \\
\text { et } \mathrm{al}^{26}\end{array}$ & 2002 & $\begin{array}{l}\text { Preliminary } \\
\text { experiment: } 7 \\
\text { cell lines, } 15 \\
\text { tissue } \\
\text { specimens } \\
\text { Validation: } \\
129 \text { tissue } \\
\text { specimens }\end{array}$ & retrospective & $\begin{array}{l}\text { uPA, tPA, } \\
\text { uPAR, PAI-I, } \\
\text { PAI-2 }\end{array}$ & $\begin{array}{l}\text { Exploratory analysis: UBC } \\
\text { cell lines (RT4, RTI I2, } \\
\text { CHA 89, T24, J82S, DAG- } \\
\text { I, TCCsup), tissue } \\
\text { Validation cohort: tissue }\end{array}$ & 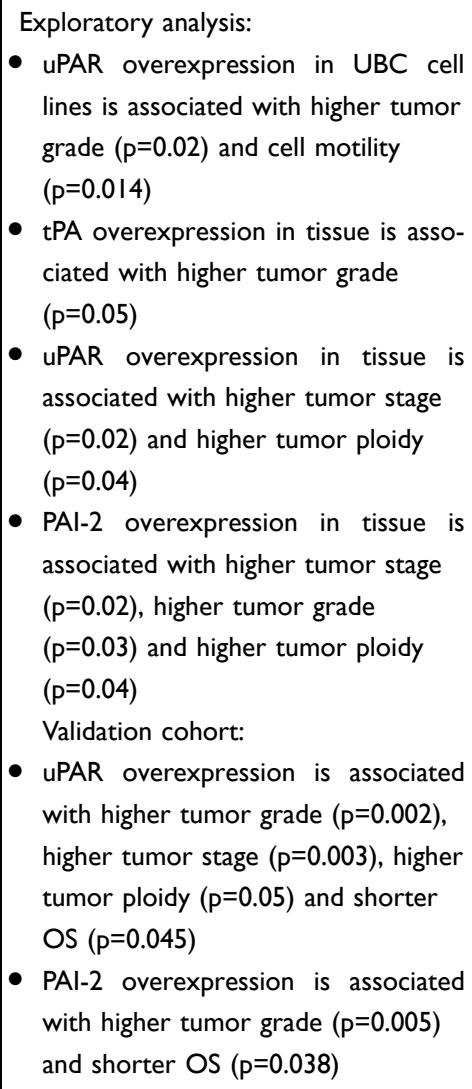 \\
\hline Hau et $\mathrm{al}^{24}$ & 2017 & 5 cell lines & not reported & UPAR & $\begin{array}{l}\text { UBC cell lines (UROtsa, } \\
\text { RT4, UM-UC-3, T24, J82) }\end{array}$ & $\begin{array}{l}\text { - uPAR overexpression is associated } \\
\text { with higher tumor stage }(p<0.05) \\
\text { uPAR gene-silencing inhibited cell } \\
\text { migration }>60 \%(p<0.005) \text { and cell } \\
\text { invasion }>80 \%(p<0.005)\end{array}$ \\
\hline
\end{tabular}

Abbreviations: UBC, urinary bladder carcinoma; uPA, urokinase-type plasminogen activator; tPA, tissue-type plasminogen activator; uPAR, uPA receptor; PAI-I, plasminogen activator inhibitor I; PAI-2, plasminogen activator inhibitor 2; OS, overall survival.

by the location of the region examined. A retrospective series of 149 patients treated with radical cystectomy addressed this. Authors found a uPAR positivity in $89 \%$ and $74 \%$ of the tumors at the invasive front and tumor core, respectively.
Patients with higher tumor stage ( $\geq \mathrm{T} 2$ ) had higher uPAR expression at the tumor core compared to those with NMIBC disease $(p<0.04) .{ }^{30}$ The findings of PAS on pathological features are summarized in Tables 1-3. 


\section{Association of PAS with Oncologic Outcomes in NMIBC}

Current evidence on the association of PAS with oncologic outcomes in NMIBC is mainly based on retrospective studies. Two small series by Hasui et al showed that overexpressed uPA is associated with a shorter progression-free survival (PFS) $\quad(\mathrm{p}<0.005)^{31}$ and a worse overall survival (OS) $(\mathrm{p}<0.005) .{ }^{32}$ Furthermore, on multivariable analysis, uPA was independently associated with PFS (relative risk $(R R)$ 5.93; $\mathrm{p}=0.011)$ and $\mathrm{OS}(\mathrm{RR} 6.22 ; \mathrm{p}=0.020){ }^{32}$ In the retrospective series of Iwata et al, authors found on multivariable analyses a significant association of uPA (Hazard ratio (HR): 1.40, $\mathrm{p}=0.006)$, uPAR (HR: 1.70, $\mathrm{p}<0.001)$ and PAI-1 (HR: 1.35, $\mathrm{p}=0.014)$ with recurrence-free survival (RFS). ${ }^{28}$ This association was independent of tumor stage and grade. Indeed, in subgroup analysis of TaG1-2 and T1G3 tumors, all three markers were independently associated with RFS. However, only uPA was associated with PFS (HR 1.68, $\mathrm{p}=0.03$ ).

Controversially, in the series by Chan et al on multivariable analysis, PAI-1 was not associated with RFS but with OS (HR: 2.58, $\mathrm{p}=0.0004){ }^{27}$

Both series are limited by the retrospective design and missing prognostic pathologic features like lymph vascular invasion and variant histology. ${ }^{33}$ Table 2 summarizes the findings for NMIBC.

Table 2 Overview of the Studies Investigating the Plasminogen Activation System (PAS) on Non-Muscle-Invasive Bladder Cancer (NMIBC)

\begin{tabular}{|c|c|c|c|c|c|c|}
\hline \multicolumn{7}{|c|}{ NMIBC Tissue } \\
\hline Author & Year & $\begin{array}{l}\text { Pat. } \\
\text { No. }\end{array}$ & $\begin{array}{l}\text { Study } \\
\text { Design }\end{array}$ & $\begin{array}{l}\text { Marker } \\
\text { Investigated }\end{array}$ & Source & Findings \\
\hline Hasui et $\mathrm{al}^{31}$ & 1994 & 42 & not reported & uPA & Tissue & - uPA overexpression is associated with shorter PFS $(p<0.005)$ \\
\hline Hasui et $\mathrm{al}^{32}$ & 1996 & 52 & prospective & uPA & Tissue & $\begin{array}{l}\text { - uPA overexpression is associated with shorter OS }(\mathrm{p}<0.005) \text { and is } \\
\text { an independent predictor for worse OS }(\mathrm{RR} 6.22 ; \mathrm{p}=0.020) \text { and } \\
\text { shorter PFS (RR 5.93; } \mathrm{p}=0.0 \mathrm{II}) \\
\text { - Muscle invasion occurred in } 2(\mathrm{I} \%) \text { patients in the uPA over- } \\
\text { expression group versus I }(3 \%) \text { in the low-expression group } \\
(\mathrm{p} \text {-value not shown) }\end{array}$ \\
\hline Iwata et $\mathrm{al}^{28}$ & 2019 & 827 & retrospective & $\begin{array}{l}\text { uPA, uPAR, } \\
\text { PAI-I }\end{array}$ & Tissue & 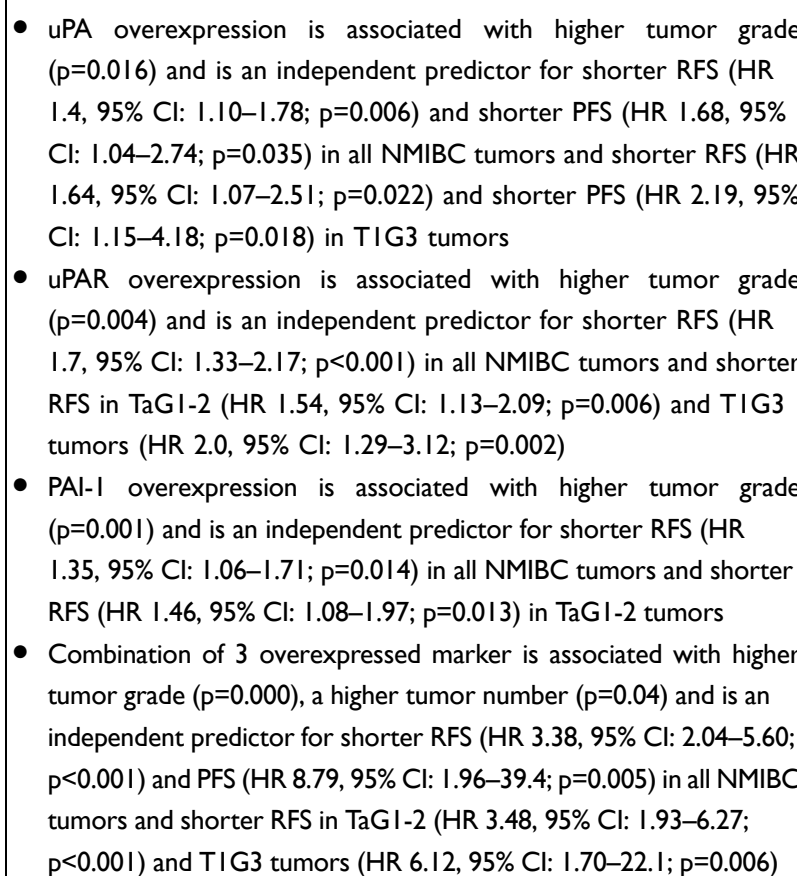 \\
\hline
\end{tabular}

Abbreviations: uPA, urokinase-type plasminogen activator; tPA, tissue-type plasminogen activator; uPAR, uPA receptor; PAI-I, plasminogen activator inhibitor I; RFS, recurrence free survival; PFS, progression free survival; OS, overall survival; RR, relative risk; HR, hazard ratio; $95 \% \mathrm{CI}, 95 \%$ confidence interval. 
Table 3 Overview of the Studies Investigating the Plasminogen Activation System (PAS) on Non-Muscle-Invasive Bladder Cancer (NMIBC) and Muscle-Invasive Bladder Cancer (MIBC)

\begin{tabular}{|c|c|c|c|c|c|c|}
\hline \multicolumn{7}{|c|}{ NMIBC and MIBC Tissue } \\
\hline Author & Year & $\begin{array}{l}\text { Pat. } \\
\text { No. }\end{array}$ & $\begin{array}{l}\text { Study } \\
\text { Design }\end{array}$ & $\begin{array}{l}\text { Marker } \\
\text { Investigated }\end{array}$ & Source & Findings \\
\hline Hasui et al ${ }^{59}$ & 1992 & 46 & not reported & uPA & Tissue & $\begin{array}{l}\text { - uPA overexpression is associated with higher tumor grade } \\
(p<0.01) \text {, tumor stage }(p<0.01) \text { and a worse CSS }(p<0.005)\end{array}$ \\
\hline $\begin{array}{l}\text { Seddighzadeh } \\
\text { et } \mathrm{al}^{37}\end{array}$ & 2002 & 194 & prospective & UPA, uPAR & Tissue & 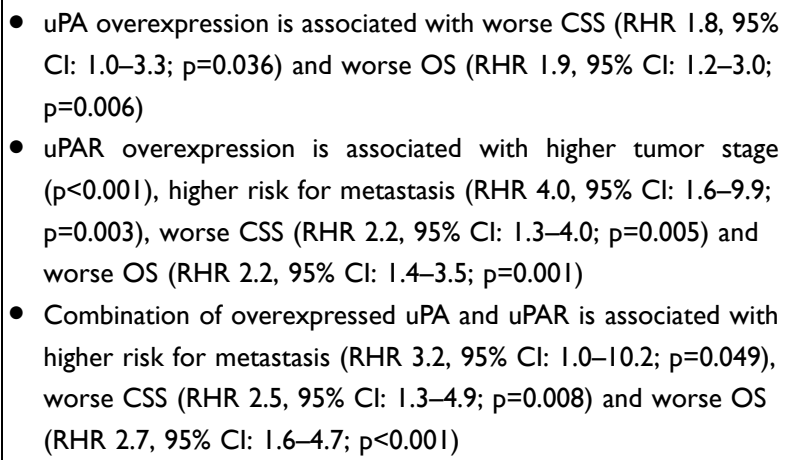 \\
\hline El Kott et $\mathrm{al}^{36}$ & 2004 & 100 & retrospective & uPA, uPAR & Tissue & $\begin{array}{l}\text { - uPA overexpression is associated with higher tumor stage } \\
(p=0.00013) \text {, lymph node metastasis }(p=0.000 \mathrm{II}) \text { and distant } \\
\text { metastasis }(p=0.0015) \\
\text { - uPAR overexpression is associated with higher tumor stage } \\
(p=0.0024) \text {, lymph node metastasis ( } p=0.026) \text {, distant metastasis } \\
(p=0.0017) \text { and is an independent predictor for worse OS (OR } \\
3.1386 ; p<0.00000 I)\end{array}$ \\
\hline $\begin{array}{l}\text { Gotanda } \\
\text { et al }\end{array}$ & 2006 & 72 & retrospective & uPA, PAI-I & Tissue & $\begin{array}{l}\text { - uPA overexpression is associated with higher tumor stage } \\
(p<0.05)\end{array}$ \\
\hline Dohn et $\mathrm{al}^{30}$ & 2015 & 149 & retrospective & UPAR & Tissue & $\begin{array}{l}\text { - uPAR overexpression in cancer cells, macrophages and myofibro- } \\
\text { blasts is associated with higher tumor grade, higher tumor stage } \\
\text { (all } \mathrm{p}<0.02 \text { ) and worse OS (HR } 2.39,95 \% \mathrm{Cl}: \mathrm{I} .15-5.01 ; \mathrm{p}=0.020) \\
\text { - uPAR overexpression in tumor core was associated with female } \\
\text { gender }(\mathrm{p}=0.0 \mathrm{I})\end{array}$ \\
\hline Dohn et $\mathrm{al}^{35}$ & 2015 & 186 & retrospective & UPAR & Tissue & $\begin{array}{l}\text { - uPAR overexpression in macrophages and myofibroblasts in the } \\
\text { tumor core is associated with higher tumor stage and lymph } \\
\text { vascular invasion (all } \mathrm{p}<0.04 \text { ) } \\
\text { - uPAR overexpression in macrophages and myofibroblasts at the } \\
\text { invasive tumor front is associated with higher tumor stage, higher } \\
\text { tumor grade and concomitant CIS (all } p<0.03 \text { ) } \\
\text { - uPAR overexpression in myofibroblasts at the invasive tumor } \\
\text { front is associated with lymph node metastasis }(\mathrm{p}=0.02 \mathrm{I})\end{array}$ \\
\hline Chan et $\mathrm{al}^{27}$ & 2017 & 939 & retrospective & PAI-I & Tissue & $\begin{array}{l}\text { - PAl-I overexpression is associated with higher tumor grade ( } 65 \% \\
\text { in high grade vs } 49 \% \text { in low grade disease; } \mathrm{p}<0.00 \mathrm{I}) \\
\text { - PAI-I overexpression independently associated with OS (HR } \\
2.58,95 \% \mathrm{Cl}: \mathrm{I} .52-4.38 ; \mathrm{p}=0.0004) \text { in NMIBC } \\
\text { - PAI-I overexpression is independently associated with OS (HR } \\
\mathrm{I} .69,95 \% \mathrm{Cl}: \mathrm{I} .09-2.62 ; \mathrm{p}=0.02) \text { in MIBC }\end{array}$ \\
\hline
\end{tabular}

(Continued) 
Table 3 (Continued).

\begin{tabular}{|c|c|c|c|c|c|c|}
\hline \multicolumn{7}{|c|}{ NMIBC and MIBC Tissue } \\
\hline Author & Year & $\begin{array}{l}\text { Pat. } \\
\text { No. }\end{array}$ & $\begin{array}{l}\text { Study } \\
\text { Design }\end{array}$ & $\begin{array}{l}\text { Marker } \\
\text { Investigated }\end{array}$ & Source & Findings \\
\hline Janisch et $\mathrm{al}^{38}$ & 2020 & 272 & retrospective & $\begin{array}{l}\text { UPA, uPAR, } \\
\text { PAI-I }\end{array}$ & Tissue & 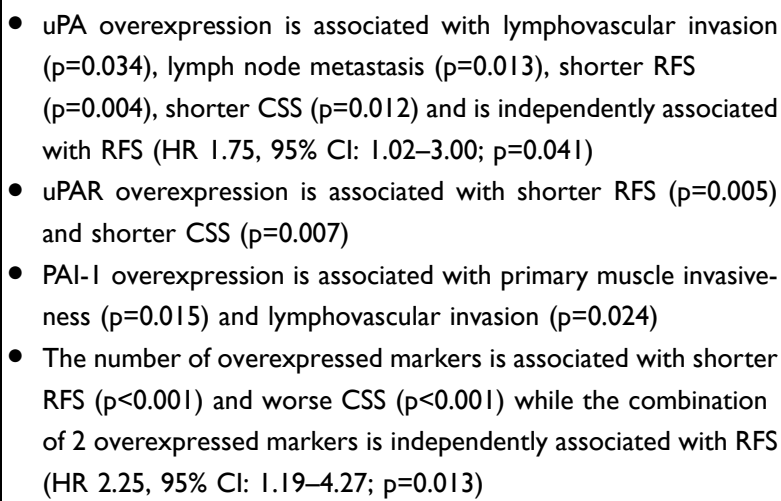 \\
\hline
\end{tabular}

Abbreviations: CIS, carcinoma in situ; uPA, urokinase-type plasminogen activator; tPA, tissue-type plasminogen activator; uPAR, uPA receptor; PAI-I, plasminogen activator inhibitor I; RFS, recurrence free survival; CSS, cancer specific survival; OS, overall survival; HR, hazard ratio; RHR, relative hazard ratio (adjusted HR for specified covariates); OR, odds ratio; $95 \% \mathrm{Cl}, 95 \%$ confidence interval.

\section{Association of PAS with Oncologic Outcomes in MIBC}

Several studies have investigated the association of tissue PAS components with oncologic outcomes in MIBC. However, the bulk of evidence remains limited to retrospective series. ${ }^{27,34-36}$ One of these studies showed an association between uPAR overexpression (in macrophages and myofibroblasts) in the tumor core with existing lymph vascular infiltration ( $\mathrm{p}=0.04, \mathrm{p}=0.014$, respectively) and at the tumor front with concomitant carcinoma in situ (CIS) $\left(\mathrm{p}=0.015, \mathrm{p}=0.026\right.$, respectively). ${ }^{35}$ Patients with metastasis at initial tumor resection showed a significantly increased uPA $(\mathrm{p}=0.0015)^{36}$ and UPAR $(p=0.0017)^{36}$ expression with a $80 \%$ probability of metastases $(p=0.003){ }^{37} \mathrm{~A}$ similar observation was made for preexisting lymph nodes metastasis (uPA $\mathrm{p}=0.00011$; uPAR $\mathrm{p}=0.026) .{ }^{36}$ In terms of cancer-specific survival (CSS), the likelihood of patients dying from their disease was shown to be $64 \%(p=0.036)$ higher in case of overexpressed uPA and $69 \%(\mathrm{p}=0.005)$ higher in case of uPAR overexpression compared to patients with normal expression levels. ${ }^{37}$ For OS, the probability of premature death is described as $69 \%(\mathrm{p}=0.001),{ }^{37} 71 \%(\mathrm{p}=0.02)^{34}$ and $76 \%$ $(\mathrm{p}<0.000001)^{36}$ higher for uPAR overexpression. With an increased uPA, the probability is $66 \%(\mathrm{p}=0.006)^{37}$ and with an increased PAI-1 $63 \%(\mathrm{p}=0.02)^{27}$ higher. Further, in an analysis of 272 patients treated with radical cystectomy, authors investigated the association of uPA, uPAR and PAI-1 with RFS and CSS. On multivariable analysis they found an association of uPA only with RFS (HR 1.75, $p=0.04$ ). Interestingly, uPA overexpression was associated with established adverse prognostic features such as lymph vascular invasion $(\mathrm{p}=0.034)$ and lymph node metastases $(p=0.013) .{ }^{38}$ Table 3 provides the findings for MIBC besides NMIBC, from studies where both have been investigated.

\section{Possible Therapeutic Approaches}

The association of the PAS components with tumorigenesis, cell proliferation, migration, adhesion and angiogenesis sets the ground for potential therapeutic approaches and development of new drugs that could be used in combination with current standards.

The urinary bladder is a well accessible organ. Therefore, the intravesical administration of topic agents for the treatment of superficial bladder cancer is a widely used approach as it maximizes the local exposure by minimizing systemic effects. Based on this rationale, the effect of intravesical PAI-1 instillation has been investigated in an orthotopic rat bladder tumor animal model. Authors found that the intravesical administration of high concentrated recombinant mutant human PAI-1 reduced the tumor size by $53 \%$. Moreover, $22 \%$ of PAI- 1 treated tumors invaded the muscle compared to $79 \%$ in the control 
group. ${ }^{39}$ Development of a drug applicable in clinical trials is warranted.

A number of studies have investigated the antitumoral effect of modulating other molecules involved in the PAS cascade.

Oka et al compared the expression levels of mRNA and protease activity of uPA as well as plasmin formation between cell cultures of non-invasive and highly invasive UBC cell lines. Using an in vitro cell invasion assay, the authors evaluated the effects of amiloride, a sodium ion transporter that competitively inhibits the catalytic activity of uPA, and urinary trypsin inhibitor (UTI) on invasion in both cell lines. They observed a substantial decrease in plasmin formation and thus a significantly reduced cellular invasion in both cell lines among amiloride and UTI $(\mathrm{p}<0.001)^{40}$

Flavonoids, bioactive compounds extracted from plants, have been shown to influence cancerogenesis, progression, invasion and metastasis. ${ }^{41}$ In UBC cell lines, the flavonoids amentoflavone and apigenin have been associate with a reduction in cancer progression and invasion. Amentoflavones have shown an inhibitory effect on tumor progression-related proteins such as VEGF, MMP-2, MMP-9 and uPA/uPAR ${ }^{42}$ while apigenin showed a significant suppression of UPAR expression after its application compared to control cells without apigenin treatment $(\mathrm{p}<0.05) .^{43}$ They also observed a reduction in the number of invading tumor cancer cells after treatment with apigenin compared to control cells $(\mathrm{p}=0.025)$. Thus, a promising suppression of tumor progression-related proteins in UBC cells in vitro is shown. Further, epidemiological studies have revealed that a flavonoid-rich diet reduces the risk of developing certain cancers, making these compounds attractive for cancer prevention. ${ }^{44}$ Therefore, in vivo studies are needed to further investigate the anti-cancer effects of flavonoids in order to make them available for future clinical practice.

\section{Future Therapeutic Approaches}

A promising therapeutic goal is the antagonization of uPA-uPAR interaction by antisense therapy, gene therapy or mainly by immunotherapy. ${ }^{45}$ These therapeutic targets have been investigated in human cell lines and animal models. The resulting downregulation of uPAR by antisense and gene therapy has been associated with increased tumor dormancy, ${ }^{46}$ reduced tumorigenesis, ${ }^{47}$ inhibition of angiogenesis ${ }^{48}$ and increased survival ${ }^{49}$ in different malignancies. The use of monoclonal antibodies as inhibitors of the UPA-uPAR interaction in various solid tumors have shown to inhibit cell proliferation, invasion, migration and adhesion in vitro. In vivo, they reduced cell proliferation, invasion, tumor count, metastasis, tumor as well as metastasis volume and improved survival. $^{50-54}$ Contrary to antisense and gene therapy, which are limited in their practicability due to a difficult delivery and the instability of these vectors, immunotherapy is an already established therapeutic procedure. Therefore, further investigations on the effects of immunotherapy targeting UPAR in UBC cell lines, in corresponding animal models and thereafter in clinical trials are necessary.

\section{Discussion}

Through the progressive understanding of the molecular landscape of UBC, a number of candidate biomarkers have emerged. In this context, the association of PAS components with pathologic features and clinical outcomes has been investigated in several series showing promising results. However, the current body of evidence is mainly based on preclinical trials and retrospective series.

UPA and UPAR have shown to be associated with tumor cell adhesion, migration and metastasis by supporting angiogenesis. $^{21-23}$ PAI-1 is mainly associated with tumor cell differentiation and is partially involved in cell migration and adhesion by its binding to ECM proteins. ${ }^{27,55}$ While the overexpression of PAS components is in general associated with higher tumor grade and stage, the literature presents conflicting results regarding the single PAS components. ${ }^{27,28,31,32,34-38}$ Explanations for this are manifold and are mainly inherent to the retrospective design of clinical studies. First and foremost, there is a case mix in clinical studies including UBC across all tumor stages. Second, there is a variety of different antibodies used for staining and the cut-off values for positivity are arbitrary set. Third, sample selection, collection, storage and handling are not standardized, even within studies. Fourth, clinical factors such as age, preexisting disease, medication or nutrition, which could influence the expression of these proteins, are not consistently evaluated. Finally, tumor heterogeneity leads to different results dependent of the region analyzed. ${ }^{30}$ Altogether, limits the reproducibility and validation of the studies and, therefore, the applicability of PAS components as biomarkers in clinical routine.

In the era of personalized medicine, several aspects in translation from biomarker discovery to clinical applicability should be considered. It is highly unlikely that the use 
of a single biomarker will be sufficient to predict the behavior of an individual malignancy. In several studies, it has been shown that the use of several biomarkers is superior to a single one. ${ }^{14,16,56,57}$ However, before a biomarker is clinically useful, it needs to be demonstrated that adding a biomarker to an existing model, based on the most important clinical and pathological factors, significantly improves its predictive accuracy. ${ }^{18,58}$ Further, before such a model can be used for individual patient care in diagnosis or treatment, its true clinical implications must be investigated in prospective and welldesigned studies.

Possible therapeutic approaches to PAS in UBC have only been sparsely investigated so far. Most of the current knowledge is based on in vitro studies that have not been further investigated in vivo. Only the investigation of intravesical PAI-1 instillation ${ }^{39}$ and the use of monoclonal antibodies targeting $\mathrm{uPAR}^{50-54}$ in animal models were performed in vivo and yielded interesting results.

\section{Conclusion}

The tissue expression of PAS components has shown to be associated with adverse pathological features and outcomes in UBC. However, these findings are based on a low level of evidence, making its further exploration in prospective trial necessary to translate the PAS components to clinically applicable biomarkers and therapeutic targets.

\section{Abbreviations}

PAS, plasminogen activation system; UBC, urinary bladder carcinoma; NMIBC, non-muscle-invasive bladder cancer; MIBC, muscle-invasive bladder cancer; uPA, urokinase-type plasminogen activator; uPAR, urokinasetype plasminogen activator receptor; PAI, plasminogen activator inhibitor; IHC, immunohistochemistry; OR, odds ratio; RR, relative risk; HR, hazard ratio; RFS, recurrence-free survival; PFS, progression-free survival; OS, overall survival; CSS, cancer-specific survival; CIS, carcinoma in situ; UTI urinary trypsin inhibitor.

\section{Funding}

Nico C. Grossmann is supported by the Zurich Cancer League. Victor M. Schuettfort, Benjamin Pradere and Ekaterina Laukhtina are supported by the EUSP Scholarship of the European Association of Urology (EAU). They are not involved in the development of this review.

\section{Disclosure}

The authors report no financial interests or other conflicts of interest in this work.

\section{References}

1. Ferlay J, Steliarova-Foucher E, Lortet-Tieulent J, et al. Cancer incidence and mortality patterns in Europe: estimates for 40 countries in 2012. Eur J Cancer. 2013;49(6):1374-1403.

2. Babjuk M, Burger M, Compérat EM, et al. European Association of Urology Guidelines on Non-muscle-invasive Bladder Cancer (TaT1 and carcinoma in situ) - 2019 update. Eur Urol. 2019;76(5):639-657.

3. Sylvester RJ, van der Meijden AP, Oosterlinck W, et al. Predicting recurrence and progression in individual patients with stage $\mathrm{Ta} T 1$ bladder cancer using EORTC risk tables: a combined analysis of 2596 patients from seven EORTC trials. Eur Urol. 2006;49(3):466-465; discussion 475-467.

4. Stein JP, Lieskovsky G, Cote R, et al. Radical cystectomy in the treatment of invasive bladder cancer: long-term results in 1054 patients. J Clin Oncol. 2001;19(3):666-675.

5. Sternberg CN, Bellmunt J, Sonpavde G, et al. ICUD-EAU International Consultation on Bladder Cancer 2012: chemotherapy for urothelial carcinoma-neoadjuvant and adjuvant settings. Eur Urol. 2013;63(1):58-66.

6. Karakiewicz PI, Shariat SF, Palapattu GS, et al. Nomogram for predicting disease recurrence after radical cystectomy for transitional cell carcinoma of the bladder. $J$ Urol. 2006;176(4 Pt 1):1354-1361; discussion 1361-1352.

7. Karakiewicz PI, Shariat SF, Palapattu GS, et al. Precystectomy nomogram for prediction of advanced bladder cancer stage. Eur Urol. 2006;50(6):1254-1260; discussion 1261-1252.

8. Kluth LA, Black PC, Bochner BH, et al. Prognostic and prediction tools in bladder cancer: a comprehensive review of the literature. Eur Urol. 2015;68(2):238-253.

9. Shariat SF, Karakiewicz PI, Palapattu GS, et al. Nomograms provide improved accuracy for predicting survival after radical cystectomy. Clin Cancer Res. 2006;12(22):6663-6676.

10. Soukup V, Čapoun O, Cohen D, et al. Risk stratification tools and prognostic models in non-muscle-invasive bladder cancer: a critical assessment from the european association of urology non-muscle-invasive bladder cancer guidelines panel. Eur Urol Focus. 2020;6(3):479-489.

11. Barbieri CE, Lotan Y, Lee RK, et al. Tissue-based molecular markers for bladder cancer. Minerva Urol Nefrol. 2010;62(3):241-258.

12. Matsushita K, Cha EK, Matsumoto K, et al. Immunohistochemical biomarkers for bladder cancer prognosis. Int J Urol. 2011;18 (9):616-629.

13. Shariat SF, Chade DC, Karakiewicz PI, et al. Combination of multiple molecular markers can improve prognostication in patients with locally advanced and lymph node positive bladder cancer. $J$ Urol. 2010;183(1):68-75.

14. Soria F, Krabbe LM, Todenhöfer T, et al. Molecular markers in bladder cancer. World J Urol. 2019;37(1):31-40.

15. Kim YK, Kim WJ. Epigenetic markers as promising prognosticators for bladder cancer. Int J Urol. 2009;16(1):17-22.

16. Shariat SF, Karakiewicz PI, Ashfaq R, et al. Multiple biomarkers improve prediction of bladder cancer recurrence and mortality in patients undergoing cystectomy. Cancer. 2008;112(2):315-325.

17. Shariat SF, Tilki D. Bladder cancer: nomogram aids clinical decision making after radical cystectomy. Nat Rev Urol. 2010;7(4):182-184.

18. Shariat SF, Lotan Y, Vickers A, et al. Statistical consideration for clinical biomarker research in bladder cancer. Urol Oncol. 2010;28(4):389-400.

19. Eapen L, Stewart D, Grimard L, et al. [Treatment of cancer of the bladder in elderly patients with an intra-arterial chemotherapy and radiotherapy combination: 10-year experience]. Cancer Radiother. 1998;2 Suppl 1:73s-76s. French. 
20. Dass K, Ahmad A, Azmi AS, Sarkar SH, Sarkar FH. Evolving role of uPA/uPAR system in human cancers. Cancer Treat Rev. 2008;34 (2):122-136.

21. Andreasen PA, Egelund R, Petersen HH. The plasminogen activation system in tumor growth, invasion, and metastasis. Cell Mol Life Sci. 2000;57(1):25-40.

22. Andreasen PA, Kjøller L, Christensen L, Duffy MJ. The urokinase-type plasminogen activator system in cancer metastasis: a review. Int J Cancer. 1997;72(1):1-22.

23. Schmitt M, Harbeck N, Thomssen C, et al. Clinical impact of the plasminogen activation system in tumor invasion and metastasis: prognostic relevance and target for therapy. Thromb Haemost. 1997;78(1):285-296.

24. Hau AM, Leivo MZ, Gilder AS, Hu JJ, Gonias SL, Hansel DE. mTORC2 activation is regulated by the urokinase receptor (UPAR) in bladder cancer. Cell Signal. 2017;29:96-106.

25. McGarvey TW, Kariko K, Barnathan ES, Thomas J, Malkowicz SB. The expression of urokinase-related genes in superficial and invasive transitional cell carcinoma. Int J Oncol. 1998;12(1):175-180.

26. Champelovier P, Boucard N, Levacher G, Simon A, Seigneurin D, Praloran V. Plasminogen- and colony-stimulating factor-1-associated markers in bladder carcinoma: diagnostic value of urokinase plasminogen activator receptor and plasminogen activator inhibitor type-2 using immunocytochemical analysis. Urol Res. 2002;30(5):301-309.

27. Chan OTM, Furuya H, Pagano I, et al. Association of MMP-2, RB and PAI-1 with decreased recurrence-free survival and overall survival in bladder cancer patients. Oncotarget. 2017;8(59):99707-99721.

28. Iwata T, Kimura S, Abufaraj M, et al. Prognostic role of the urokinase plasminogen activator (UPA) system in patients with nonmuscle invasive bladder cancer. Urol Oncol. 2019;37(10):774-783.

29. Thomsen MBH, Nordentoft I, Lamy P, et al. Comprehensive multiregional analysis of molecular heterogeneity in bladder cancer. Sci Rep. 2017;7(1):11702.

30. Dohn LH, Illemann M, Hoyer-Hansen G, et al. Urokinase-type plasminogen activator receptor (UPAR) expression is associated with T-stage and survival in urothelial carcinoma of the bladder. Urol Oncol. 2015;33(4):165e115-124.

31. Hasui Y, Marutsuka K, Nishi S, Kitada S, Osada Y, Sumiyoshi A. The content of urokinase-type plasminogen activator and tumor recurrence in superficial bladder cancer. J Urol. 1994;151(1):16-19; discussion 19-20.

32. Hasui Y, Marutsuka K, Asada Y, Osada Y. Prognostic value of urokinase-type plasminogen activator in patients with superficial bladder cancer. Urology. 1996;47(1):34-37.

33. DA D, Abufaraj M, Susani M, et al. Accurate prediction of progression to muscle-invasive disease in patients with pT1G3 bladder cancer: a clinical decision-making tool. Urol Oncol. 2018;36 (5):239.e231-239.e237.

34. Dohn LH, Illemann M, Høyer-Hansen G, et al. Urokinase-type plasminogen activator receptor (UPAR) expression is associated with T-stage and survival in urothelial carcinoma of the bladder. Urol Oncol. 2015;33(4):165.e115-124.

35. Dohn LH, Pappot H, Iversen BR, et al. uPAR expression pattern in patients with urothelial carcinoma of the bladder-possible clinical implications. PLoS One. 2015;10(8):e0135824.

36. El-Kott AF, Khalil AM, El-Kenawy Ael M. Immunohistochemical expressions of UPA and its receptor UPAR and their prognostic significant in urinary bladder carcinoma. Int Urol Nephrol. 2004;36 (3):417-423.

37. Seddighzadeh M, Steineck G, Larsson P, et al. Expression of UPA and UPAR is associated with the clinical course of urinary bladder neoplasms. Int $J$ Cancer. 2002;99(5):721-726.

38. Janisch F, D'Andrea D, Iwata $T$, et al. The prognostic value of the urokinase-plasminogen activator system (uPA) in bladder cancer patients treated with radical cystectomy (RC). Urol Oncol. 2020;38 (5):423-432.
39. Chen SC, Henry DO, Hicks DG, Reczek PR, Wong MK. Intravesical administration of plasminogen activator inhibitor type-1 inhibits in vivo bladder tumor invasion and progression. $J$ Urol. 2009;181 (1):336-342.

40. Oka N, Okumura Y, Kanayama H-O, et al. Amiloride and urinary trypsin inhibitor inhibit urothelial cancer invasion. Eur Urol. 2003;44 (6):737-741

41. Liskova A, Koklesova L, Samec M, et al. Flavonoids in cancer metastasis. Cancers (Basel). 2020;12:6.

42. Chiang CH, Yeh CY, Chung JG, Chiang IT, Hsu FT. Amentoflavone induces apoptosis and reduces expression of anti-apoptotic and metastasis-associated proteins in bladder cancer. Anticancer Res. 2019;39(7):3641-3649.

43. Xia Y, Yuan M, Li S, et al. Apigenin Suppresses the IL-1ß-induced expression of the urokinase-type plasminogen activator receptor by inhibiting MAPK-mediated AP-1 and NF- $\mathrm{kB}$ signaling in human bladder cancer T24 Cells. J Agric Food Chem. 2018;66(29): 7663-7673.

44. Shukla S, Gupta S. Apigenin: a promising molecule for cancer prevention. Pharm Res. 2010;27(6):962-978.

45. Mazar AP. The urokinase plasminogen activator receptor (uPAR) as a target for the diagnosis and therapy of cancer. Anticancer Drugs. 2001;12(5):387-400.

46. Aguirre Ghiso JA, Kovalski K, Ossowski L. Tumor dormancy induced by downregulation of urokinase receptor in human carcinoma involves integrin and MAPK signaling. $J$ Cell Biol. 1999;147 (1):89-104.

47. Mohan PM, Chintala SK, Mohanam S, et al. Adenovirus-mediated delivery of antisense gene to urokinase-type plasminogen activator receptor suppresses glioma invasion and tumor growth. Cancer Res. 1999;59(14):3369-3373.

48. Li H, Lu H, Griscelli F, et al. Adenovirus-mediated delivery of a uPA/ uPAR antagonist suppresses angiogenesis-dependent tumor growth and dissemination in mice. Gene Ther. 1998;5(8):1105-1113.

49. Li H, Griscelli F, Lindenmeyer F, et al. Systemic delivery of antiangiogenic adenovirus AdmATF induces liver resistance to metastasis and prolongs survival of mice. Hum Gene Ther. 1999;10 (18):3045-3053.

50. Xu X, Cai Y, Wei Y, et al. Identification of a new epitope in uPAR as a target for the cancer therapeutic monoclonal antibody ATN-658, a structural homolog of the uPAR binding integrin CD11b $(\alpha \mathrm{M})$. PLoS One. 2014;9(1):e85349.

51. Kenny HA, Leonhardt P, Ladanyi A, et al. Targeting the urokinase plasminogen activator receptor inhibits ovarian cancer metastasis. Clin Cancer Res. 2011;17(3):459-471.

52. Bauer TW, Liu W, Fan F, et al. Targeting of urokinase plasminogen activator receptor in human pancreatic carcinoma cells inhibits c-Met- and insulin-like growth factor-I receptor-mediated migration and invasion and orthotopic tumor growth in mice. Cancer Res. 2005;65(17):7775-7781.

53. Rabbani SA, Ateeq B, Arakelian A, et al. An anti-urokinase plasminogen activator receptor antibody (ATN-658) blocks prostate cancer invasion, migration, growth, and experimental skeletal metastasis in vitro and in vivo. Neoplasia. 2010;12(10):778-788.

54. Van Buren G 2nd, Gray MJ, Dallas NA, et al. Targeting the urokinase plasminogen activator receptor with a monoclonal antibody impairs the growth of human colorectal cancer in the liver. Cancer. 2009;115 (14):3360-3368.

55. Duffy MJ. The urokinase plasminogen activator system: role in malignancy. Curr Pharm Des. 2004;10(1):39-49.

56. Rosser CJ, Ross S, Chang M, et al. Multiplex protein signature for the detection of bladder cancer in voided urine samples. $J$ Urol. 2013;190(6):2257-2262.

57. Srougi V, Reis ST, Viana N, et al. Prospective evaluation of a urinary biomarker panel to detect and predict recurrence of non-muscleinvasive bladder cancer. World J Urol. 2020. 
58. Bensalah K, Montorsi F, Shariat SF. Challenges of cancer biomarker profiling. Eur Urol. 2007;52(6):1601-1609.

59. Hasui Y, Marutsuka K, Suzumiya J, Kitada S, Osada Y, Sumiyoshi A. The content of urokinase-type plasminogen activator antigen as a prognostic factor in urinary bladder cancer. Int J Cancer. 1992;50 (6):871-873.
60. Gotanda T, Haraguchi M, Tachiwada T, et al. Molecular basis for the involvement of thymidine phosphorylase in cancer invasion. Int J Mol Med. 2006;17(6):1085-1091.

\section{Publish your work in this journal}

OncoTargets and Therapy is an international, peer-reviewed, open access journal focusing on the pathological basis of all cancers, potential targets for therapy and treatment protocols employed to improve the management of cancer patients. The journal also focuses on the impact of management programs and new therapeutic

Submit your manuscript here: https://www.dovepress.com/oncotargets-and-therapy-journal agents and protocols on patient perspectives such as quality of life, adherence and satisfaction. The manuscript management system is completely online and includes a very quick and fair peer-review system, which is all easy to use. Visit http://www.dovepress.com/ testimonials.php to read real quotes from published authors. 